\title{
Incidence of cutaneous malignant melanoma in the Czech Republic: The risks of sun exposure for adolescents
}

\author{
J. VRANOVA ${ }^{1,2, *}$, M. ARENBERGEROVA ${ }^{3}$, P. ARENBERGER 3 , J. STANEK ${ }^{1}$, A. VRANA ${ }^{4}$, J. ZIVCAK ${ }^{5}$, J. ROSINA ${ }^{2,1}$ \\ ${ }^{1}$ Department of Medical Biophysics and Medical Informatics, $3^{\text {rd }}$ Faculty of Medicine, Charles University, Prague, Czech Republic; ${ }^{2}$ Faculty of Bio- \\ medical Engineering, Czech Technical University in Prague, Kladno, Czech Republic; ${ }^{3}$ Department of Dermatovenerology, $3^{\text {rd }}$ Faculty of Medicine, \\ Charles University, Prague, Czech Republic; ${ }^{4} 2^{\text {nd }}$ Faculty of Medicine, Charles University, Prague, Czech Republic; ${ }^{5}$ Department of Biomedical \\ Engineering, Automation and Measurement, Faculty of Mechanical Engineering, Technical University of Kosice, Slovak Republic
}

*Correspondence: jana.vranova@lf3.cuni.cz

Received October 24, 2011 / Accepted December 12, 2011

\begin{abstract}
The Czech Republic reported one of the highest incidence rate in cutaneous melanoma (CM) in Europe and because this incidence has been increasing, mainly among young people, the main goal of our study was to establish sun exposure behavior risk factors for $\mathrm{CM}$ formation and to evaluate whether the young generation of Czechs is exposed to a higher risk of CM than the older generation. A questionnaire-based case-control study was conducted. We obtained 978 completed questionnaires: 216 from patients with CM and 762 from healthy respondents. The healthy individuals were further divided to adolescents $(n=460)$ and older respondents $(n=302)$. Three logistic regression models were developed: 1 . patients with $\mathrm{CM}$ vs. healthy older respondents, 2 . adolescents vs. healthy older respondents, and 3. patients with CM vs. adolescents. The main risk factors for all three models were the number of sunburn episodes and the use of the sunscreen in the childhood. The most alarming results for adolescents included: all day sun exposure, including times of maximum risk (11 AM to 3 PM), inadequate use of sunscreen in adulthood, and frequent mountain holidays. Our results show that sun-safety in the young generation is satisfactory, when the responsibility for sun exposure behavior is in the hands of their parents; however, when children become adolescents, they become immune to sun-safety and risk prevention campaigns and their behavior becomes much more risky. Our results further suggest the sun-safety campaigns need to be modified in such a way as to have greater impact and influence on adolescent sun-risk behaviors.
\end{abstract}

Key words: UV radiation, cutaneous melanoma, adolescents, prevention campaign, risk factors, biomedical engineering

Since the 1970s a significant increase in the incidence of cutaneous melanoma (CM) has been observed world-wide [1]; this is no less true in the Czech Republic, which surprisingly has one of the highest rates in Europe [2,3].

Numerous epidemiological studies have identified genetics, the physical environment, socio-economic conditions $[4,5]$, and patterns of sun exposure behavior as risk factors for melanoma. The ultraviolet component of sun exposure has been demonstrated as the major environmental factor for skin cancers [6]. The risk of CM is associated with the whole-of-life dose of sun exposure as well as with intermittent severe sunburn episodes, particularly during childhood [7,8]. Risks are also elevated with high levels of childhood and adolescence sun exposure despite avoidance of sunburn $[9,10]$ and with adult exposure particularly where individuals with unacclimatised skin (e.g. office workers) enjoy outdoor hobbies and regular holidays at the seaside or in the mountains $[11,12]$.

The Czech Republic, based on the incidence of cutaneous melanoma from 2008 (latest published data, IHIS 2011), has one of the highest rates of CM in Europe and constitutes an exception relative to other Central European countries. In 2008 the reported crude annual incidence of cutaneous melanoma in the Czech Republic was 19.6 per 100,000 inhabitants for men and 16.5 per 100,000 inhabitants for women. The agestandardized incidence rate per 100,000 European standard population was 17.7 for men and 13.0 for women. In addition, incidence rates are now steeply increasing in younger age categories, with women between 25 - 29 years being the most vulnerable. Moreover, the Czech Republic shows very high yearly increments of erythemal UV radiation, measured 
at the Earth's surface [13]; however these increases cannot explain the upsurge in malignant melanoma. One of the most striking features of the CM epidemic is its association with changing sun-risk behaviors. The main goal of our study was to evaluate the impact of sun exposure behavior factors on CM occurrence, and to evaluate whether the young generation is exposed to higher risks of disease than the older generation.

A questionnaire-based investigation of sun exposure behavior was conducted by examining 216 patients with $\mathrm{CM}$ $($ Group $=$ MELANOMA) and 762 healthy controls. Healthy respondents were further divided according to age; those 20 and older (Group = OLD, N = 302) and those younger than 20 years $($ Group $=$ YOUNG, $N=460)$.

\section{Patients and methods}

Patients and Questionnaire. The study questionnaire was prepared by specialists from the Dermatovenerological Clinic of the Královské Vinohrady University Hospital and of the $3^{\text {rd }}$ Faculty of Medicine, Charles University, Prague, Czech Republic. The questionnaire included 19 questions about age, gender, phototype, family and respondent's history of malignant melanoma, presence of numerous melanotic nevi, sunbathing behavior during childhood and adulthood and solarium visits. Sunbathing during childhood included number of sunburns episodes and use of sunscreen. Sunbathing during adulthood (older than 18 years in young respondents) included sunbathing frequency, how much time the skin had been exposed to the sun, activities during which sunbathing takes place, the number and regularity of summer and winter holidays at the seaside and in the mountains, use of sunscreens and the number of sunscreen applications during sunbathing. The data collection itself was done over 7 months, from January to July 2010 . We received 978 completed questionnaires. The first group included 216 (average age $53.57 \pm 14.75$ ) questionnaires from those with diagnosed $\mathrm{CM}$, at the Dermatovenerological Clinic of the Královské Vinohrady University Hospital. The second group included 762 completed questionnaires from participants without diagnosed CM. These healthy individuals were further divided to a group of young persons, which were randomly selected from first-year students at the $3^{\text {rd }}$ Faculty of Medicine, Charles University, Prague and from the Faculty of Biomedical Engineering, Czech Technical University, Prague ( $\mathrm{N}=460$; average age $19.87 \pm 1.16)$ and a group of older participants $(\mathrm{N}=302$; average age $51.07 \pm 10.11$ ), which were recruited as control subjects after responding to a notice posted in the medical faculties and faculty hospitals of Charles University, Prague. These volunteers were eligible to participate in the study if they did not have an active malignant melanoma during the time of the study and if they reported to be of Caucasian ethnicity. The selection was conducted in a manner to achieve a similar age distribution in this group of respondents as in the group of oncological patients. Written informed consent was obtained from all patients and healthy participants, and the study was approved by the local ethics committee of the $3^{\text {rd }}$ Medical Faculty, Charles University, Prague.

Exact questions and the answers for all respondent groups are summarized in Table 1.

Statistical Analysis. The results are presented using descriptive statistics: frequencies and percentages; and Pearson's chi-square test was used to examine the association between category variables. In order to evaluate the effect of individual sun exposure risk factors on CM formation, in the first part of our study a multivariate logistic regression model for two respondent groups - patients with CM vs. the group of older, healthy persons was developed. Candidate predictor variables included in the logistic model were as follows (reference category marked in italics): phototype with the categories: I. Skin always turns red, never turns brown, II. Skin always turns red, sometimes turns brown, III. Skin rarely turns red, always turns brown, IV. Skin never turns red, always turns brown and V. Skin never turns red, black hair; hair color - Red, Fair, Brown and Black; eye color - Blue, Green, Grey, Brown; family history of melanoma (Yes vs. No); melanoma in the patient's history (Yes vs. No); skin cancer in patient's history (Yes vs. No); immunosuppression (Yes vs. No); more than 50 freckles and/or melanocytic nevi (Yes vs. No); sunburns during childhood with categories: Never, Occasionally (less than ten), Frequent (more than ten); use of sunscreens during childhood with categories: Never, Occasionally, Regularly; sunbathing in adulthood: - Never, A few days during summer, Throughout the whole summer; use of sunscreens in adulthood with categories: Never, Occasionally, Regularly (more than five applications during sunbathing); exposure to the sun: - Never, During outdoor hobbies (mainly gardening, going to the cottage during weekend), During active sunbathing; time duration of sun exposure: - Until 11 AM and after 3 PM, All day long; number of holidays at the seaside: - Never, Occasionally, Every summer; number of holidays in the mountains with categories: Never, Occasionally, Every winter, spring and summer; and number of solarium visits: - Never, less than 10 times per year and More than 10 times per year.

Using all predictive variables in the first model no statistically significant genetics and anamnestic factors were found (data not shown). Moreover, our young respondents were in the age category of less than twenty years old, where malignant melanoma are rare [14] and in our sample none reported malignant melanoma during the study or in their personal history. The main reason for a low incidence of CM in the younger age categories is the long latency of malignant melanomas $[15,16]$. Thus the full manifestation of the influence of genetic and anamnestic factors was very unlikely in this age category as well as the influence of sun exposure behaviour patterns. We cannot affect the genetic and anamnestic factors; we can only influence sun exposure and sun protection behavior of the young generation. Many publications provide clear evidence that unsuitable sunbathing during childhood, no use of sunscreens, severe sunburn episodes in spite of sun exposure control in later life and solarium visits play an important 
Table 1. Answers to questions of the questionnaire (frequency and percentage) from three respondent groups: Patients with malignant melanoma, Healthy older respondents and Healthy adolescents

\begin{tabular}{|c|c|c|c|c|c|c|c|c|c|}
\hline \multirow[b]{2}{*}{ Variable } & \multicolumn{2}{|c|}{$\begin{array}{c}\text { Patients } \\
\text { with cutaneous } \\
\text { melanoma } \\
\mathrm{N}=216\end{array}$} & \multicolumn{2}{|c|}{$\begin{array}{l}\text { Healthy } \\
\text { respondents } \\
\text { OLD } \\
\mathrm{N}=302\end{array}$} & \multicolumn{2}{|c|}{$\begin{array}{l}\text { Healthy } \\
\text { respondents } \\
\text { YOUNG } \\
\mathrm{N}=460\end{array}$} & \multirow{2}{*}{$\begin{array}{l}\text { MELANOMA } \\
\text { vs. } \\
\text { OLD } \\
\\
\\
\end{array}$} & \multirow{2}{*}{$\begin{array}{c}\text { OLD } \\
\text { vs. } \\
\text { YOUNG } \\
\text { values of } \chi^{2}-\mathrm{t}\end{array}$} & \multirow{2}{*}{$\begin{array}{c}\text { MELANOMA } \\
\text { vs. } \\
\text { YOUNG } \\
\text { test }\end{array}$} \\
\hline & $\mathrm{N}$ & $\%$ & $\mathrm{~N}$ & $\%$ & $\mathrm{~N}$ & $\%$ & & & \\
\hline \multicolumn{10}{|c|}{ 型 } \\
\hline Female & 92 & 42.59 & 186 & 61.59 & 300 & 65.22 & \multirow{2}{*}{0.003} & 0.471 & 0.00009 \\
\hline $\begin{array}{l}\text { Male } \\
\text { Phototype }\end{array}$ & 124 & 57.41 & 116 & 38.41 & 160 & 34.78 & & $0.4 / 1$ & 0.00009 \\
\hline Skin always turns red, never turns brown & 6 & 2.78 & 14 & 4.64 & 12 & 2.61 & & & \\
\hline Skin always turns red, sometimes turns brown ${ }^{\star}$ & 134 & 62.03 & 96 & 31.79 & 106 & 23.04 & & & \\
\hline Skin rarely turns red, always turns brown & 74 & 34.25 & 158 & 52.32 & 270 & 58.70 & $<0.00001$ & 0.239 & $<0.00001$ \\
\hline Skin never turns red, always turns brown & - & - & 28 & 9.27 & 56 & 12.17 & & & \\
\hline Skin never turns red, dark hair & 2 & 0.96 & 4 & 1.32 & 14 & 2.95 & & & \\
\hline Hair color & & & & & & & & & \\
\hline Red & 8 & 3.70 & 22 & 7.28 & 18 & 3.91 & & & \\
\hline Fair & 56 & 25.93 & 48 & 15.89 & 90 & 19.57 & & & \\
\hline Brown & 144 & 66.67 & 208 & 68.87 & 230 & 71.74 & 0.113 & 0.242 & 0.632 \\
\hline Black & 8 & 3.70 & 22 & 7.28 & 20 & 4.35 & & & \\
\hline Eyes color & & & & & & & & & \\
\hline Blue & 96 & 44.44 & 98 & 32.45 & 136 & 29.57 & & & \\
\hline Green & 18 & 8.33 & 84 & 27.81 & 116 & 25.22 & 0001 & 370 & 0001 \\
\hline Gray & 14 & 6.48 & 22 & 7.28 & 22 & 4.78 & 0.001 & $0.3 / 0$ & 0.001 \\
\hline Brown & 86 & 39.81 & 96 & 31.79 & 184 & 40.00 & & & \\
\hline Melanoma in family & & & & & & & & & \\
\hline No & 202 & 93.52 & 290 & 96.03 & 438 & 95.22 & & & \\
\hline Yes & 14 & 6.48 & 12 & 3.97 & 22 & 4.78 & 0.362 & 0.708 & 0.517 \\
\hline Melanoma in patient's history & & & & & & & & & \\
\hline No & 196 & 90.74 & 302 & 100 & 458 & 99.57 & & & \\
\hline Yes & 20 & 9.26 & - & - & - & - & $<0.00001$ & - & $<0.00001$ \\
\hline Skin cancer in patient's history & & & & & & & & & \\
\hline No & 200 & 92.59 & 296 & 98.01 & 454 & 98.70 & & & \\
\hline Yes & 14 & 6.48 & 6 & 1.99 & 4 & 0.43 & 0.07 & 0.149 & 0.07 \\
\hline Immunosupression & & & & & & & & & \\
\hline No & 110 & 97.22 & 294 & 97.35 & 450 & 97.83 & 0950 & & \\
\hline Yes & 6 & 2.78 & 8 & 2.65 & 4 & 1.74 & 0.950 & 0.549 & 0.536 \\
\hline More than 50 freckles or/and melanocytic nevi & & & & & & & & & \\
\hline No & 104 & 48.15 & 222 & 73.51 & 352 & 76.52 & & & \\
\hline Yes & 112 & 51.85 & 80 & 26.49 & 108 & 23.48 & $<0.00001$ & 0.346 & $<0.00001$ \\
\hline Sun burns in childhood & & & & & & & & & \\
\hline Never & 18 & 8.33 & 100 & 33.11 & 288 & 62.61 & & & \\
\hline Occasionally (less than 10 ) & 160 & 74.07 & 162 & 53.64 & 158 & 34.35 & $<0.00001$ & $<0.00001$ & $<0.00001$ \\
\hline Frequent (more than 10) & 38 & 17.59 & 38 & 12.58 & 6 & 1.30 & & & \\
\hline Use of the sunscreen in the childhood & & & & & & & & & \\
\hline Never & 144 & 68.52 & 122 & 40.40 & 26 & 5.65 & & & \\
\hline Occasionally & 52 & 24.07 & 140 & 46.36 & 196 & 42.61 & 0.00005 & $<0.00001$ & $<0.00001$ \\
\hline Regularly & 14 & 6.48 & 36 & 11.92 & 232 & 50.43 & & & \\
\hline Sunbathing in adulthood & & & & & & & & & \\
\hline Never & 14 & 6.48 & 26 & 8.61 & 36 & 7.82 & & & \\
\hline Few days in the summer & 180 & 83.33 & 198 & 65.56 & 320 & 69.57 & 0.004 & 0.672 & 0.020 \\
\hline Throughout the whole summer & 22 & 10.19 & 78 & 25.82 & 102 & 22.17 & & & \\
\hline Use of the sunscreen in the adulthood & & & & & & & & & \\
\hline Never & 32 & 14.81 & 30 & 9.93 & 24 & 5.21 & & & \\
\hline Occasionally & 110 & 50.93 & 82 & 27.15 & 304 & 66.09 & 0.00003 & 0.0002 & 0.003 \\
\hline Regularly (more than 5 times per sun tanning) & 74 & 34.26 & 190 & 62.91 & 130 & 28.26 & & & \\
\hline Exposure to sun radiation & & & & & & & & & \\
\hline Never & 14 & 6.48 & 22 & 7.28 & 18 & 3.91 & & & \\
\hline At outdoor hobby & 52 & 24.07 & 26 & 8.61 & 16 & 3.48 & 0.003 & 0.360 & $<0.00001$ \\
\hline Active sunbathing (sports) & 150 & 69.44 & 254 & 84.11 & 426 & 92.61 & & & \\
\hline Time duration of sun exposure & & & & & & & & & \\
\hline Until $11 \mathrm{AM}$ and from $03 \mathrm{PM}$ & 68 & 31.48 & 200 & 66.22 & 126 & 27.39 & & & \\
\hline All day long & 144 & 66.67 & 96 & 31.79 & 324 & 70.43 & $<0.00001$ & 0.00002 & 0.282 \\
\hline Holidays at the seaside & & & & & & & & & \\
\hline Never & 12 & 5.56 & 24 & 7.95 & 24 & 5.22 & & & \\
\hline Occasionally & 114 & 52.78 & 174 & 57.62 & 282 & 61.30 & 0.364 & 0.528 & 0.318 \\
\hline Every summer & 90 & 41.67 & 100 & 33.11 & 154 & 33.47 & & & \\
\hline Holidays in the mountains & & & & & & & & & \\
\hline Never & 22 & 10.19 & 52 & 17.22 & 22 & 4.78 & & & \\
\hline Occasionally & 126 & 58.33 & 144 & 47.68 & 198 & 43.04 & 0.082 & 0.0001 & 0.002 \\
\hline Every winter and every spring & 68 & 31.48 & 62 & 20.53 & 234 & 50.87 & & & \\
\hline Solarium & & & & & & & & & \\
\hline Never & 202 & 93.52 & 246 & 81.46 & 334 & 72.61 & & & \\
\hline Less than 10 times per year & 10 & 4.63 & 34 & 11.26 & 96 & 20.87 & 0.025 & 0.053 & 0.00006 \\
\hline More than 10 times per year & 4 & 1.85 & 20 & 6.62 & 30 & 6.52 & & & \\
\hline
\end{tabular}

*The reference category of categorical variables for logistic regression model are marked in italics 
role in the etiology of CM with over $80 \%$ [17] of cases being attributed to sun exposure. In addition, many publications indicate that the young generation is the most resistant to all preventive campaigns [18-20]. Therefore genetic and anamnestic factors were excluded from the statistical analysis and the three identical logistic regression models - patients with $\mathrm{CM}$ vs. older healthy individuals, adolescents vs. older healthy individuals and patients with CM vs. adolescents - were built. The following candidate predictors were used: more than 50 freckles and/or melanocytic nevi; sunburns during childhood; use of sunscreens during childhood; sunbathing in adulthood; use of sunscreens in adulthood; sun exposure; time duration of sun exposure; number of holidays at the seaside; number of holidays in the mountains and number of solarium visits.

Using the last two constructed logistic regression models we were able to assess whether sun exposure behavior of the young generation had not become more risky compared to both older generations.

The results are presented as odds ratios (ORs) together with their $95 \%$ confidence intervals (CIs).

A

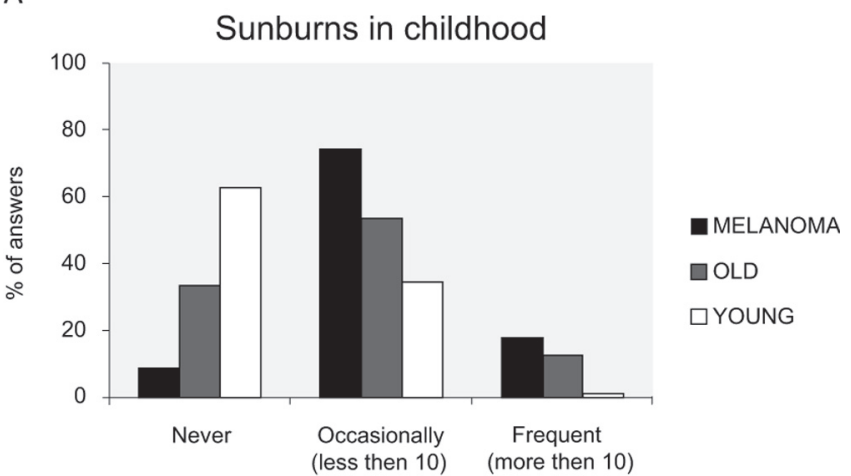

Figure 1a: Percentage of answers to the question "Sunburns in childhood" for all 3 groups of respondents

C

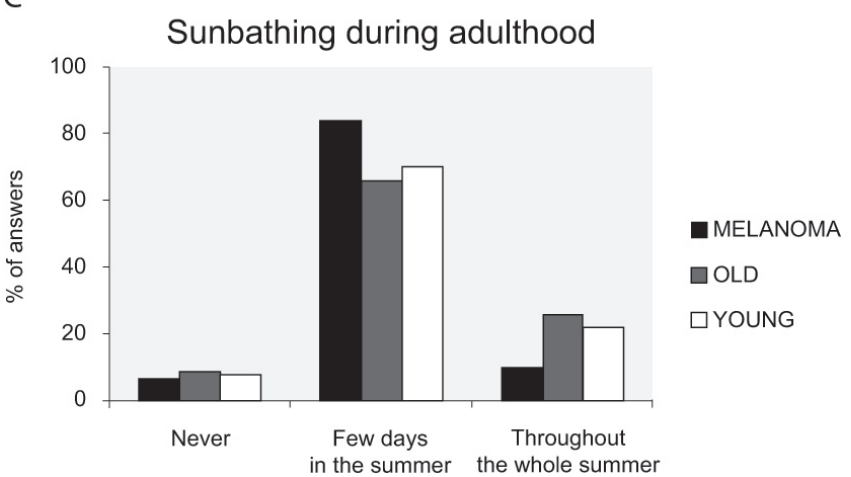

Figure 1c: Percentage of answers to the question "Sunbathing during adulthood" for all 3 groups of respondents
The statistical programs STATISTICA version 9 from StatSoft, Inc. and SPSS 18 from SPSS, Inc. were used for the statistical analysis. All results with a probability $\mathrm{p}<0.05$ were considered to be statistically significant.

\section{Results}

Descriptive Statistics. The answers (frequency and percentage representations) to all questions from all respondent groups are summarized in Table 1. A graphical presentation of percentages of answers is presented in Figs. 1a - 1i.

Using Table 1 and Figs. 1a to $1 \mathrm{i}$ it is possible to evaluate changes in the behavior of the young generation compared to both older groups. Some results confirm the responsible behavior of the young generation, while other results are alarming and indicate an increased risk of malignant melanoma.

Satisfactory results include sun protection while sunbathing during childhood: no sunburns during childhood occurred in $62.61 \%$ of young respondents, this value was $33.11 \%$ in older healthy individuals ( $\mathrm{p}<0.0001)$, and only $8.33 \%$ in oncological

B

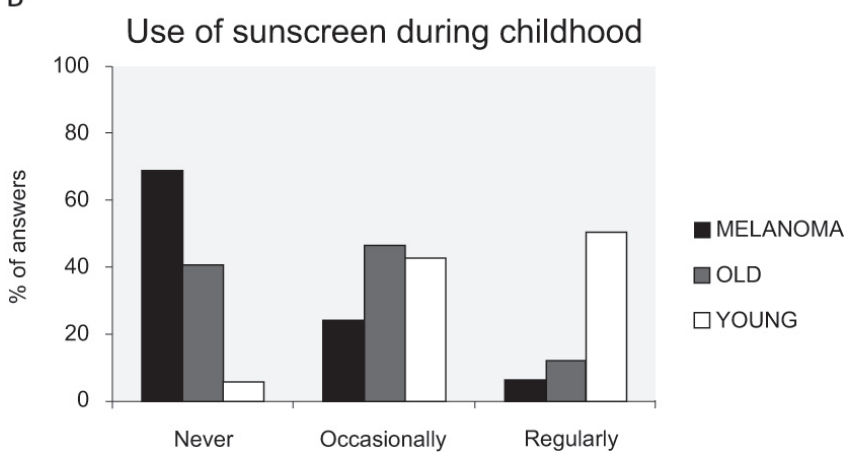

Figure 1b: Percentage of answers to the question "Use of sunscreen during childhood" for all 3 groups of respondents

D

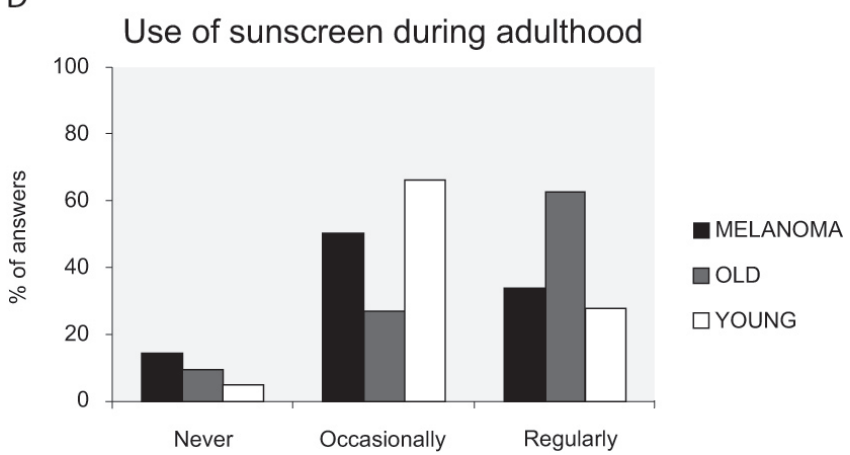

Figure 1d: Percentage of answers to the question "Use of sunscreen during adulthood" for all 3 groups of respondents 
E

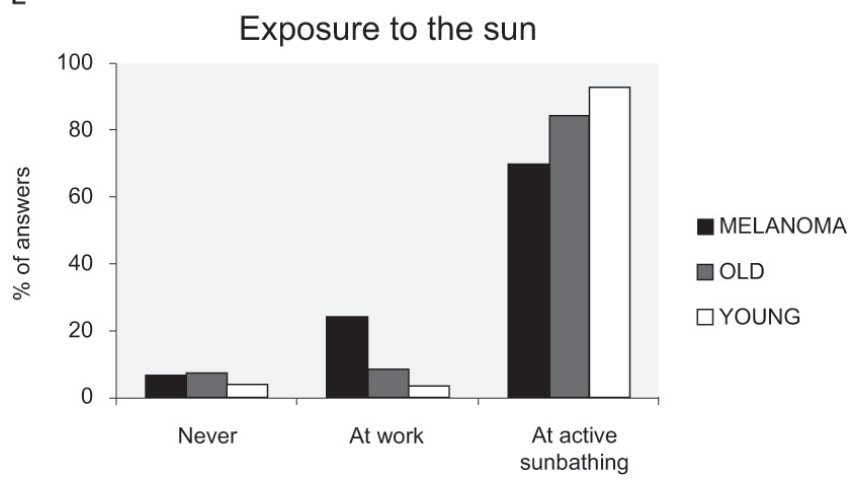

Figure 1e: Percentage of answers to the question "Exposure to the sun" for all 3 groups of respondents

G

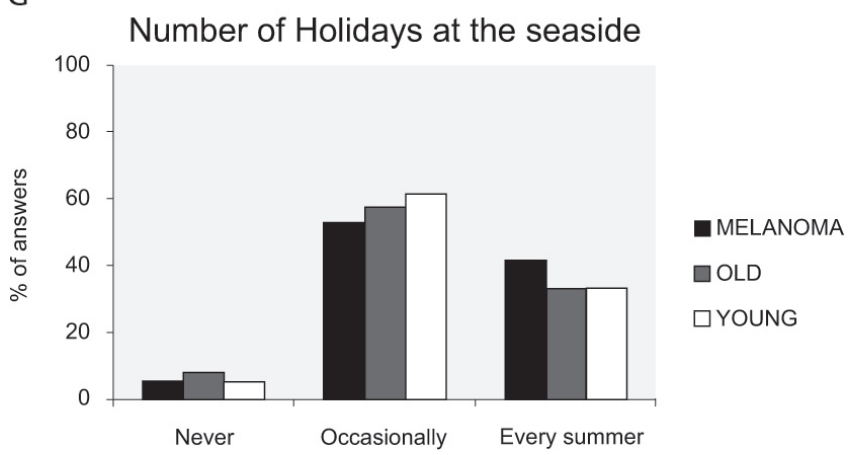

Figure 1g: Percentage of answers to the question "Number of Holidays at the seaside" for all 3 groups of respondents

I

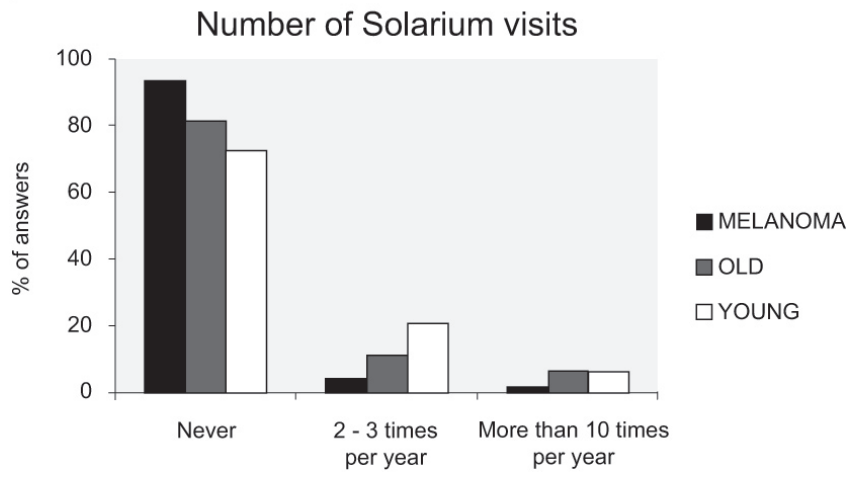

Figure 1i: Percentage of answers to the question "Number of Solarium visits" for all 3 groups of respondents

patients ( $\mathrm{p}<0.0001)$; sunscreens were used regularly during childhood by $50.43 \%$ of young people compared to $11.92 \%$ of older ones ( $\mathrm{p}<0.0001)$ and only $6.48 \%$ of CM patients $(\mathrm{p}<$ 0.0001 ). Other satisfactory results, in which similar behaviors,
$\mathrm{F}$

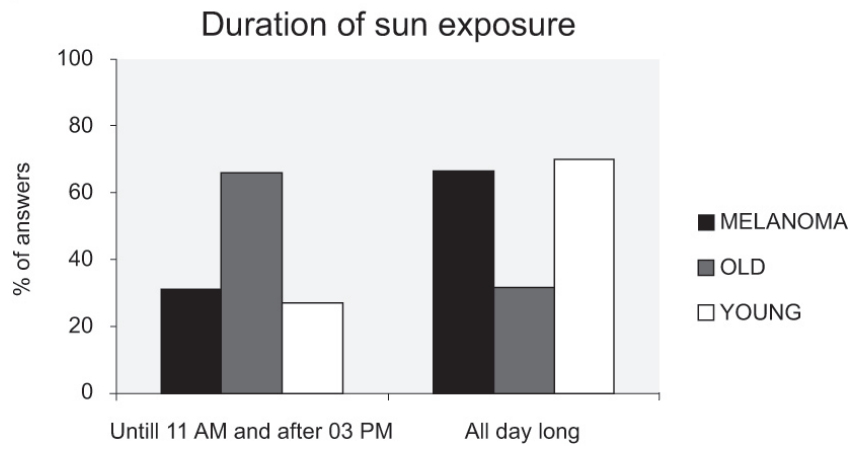

Figure 1f: Percentage of answers to the question "Duration of sun exposure" for all 3 groups of respondents

$\mathrm{H}$

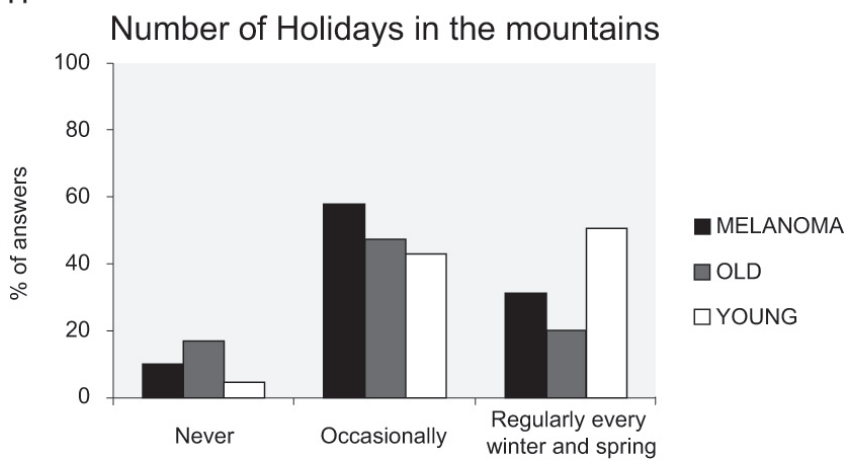

Figure 1h: Percentage of answers to the question "Number of Holidays in the mountains" for all 3 groups of respondents

among the young as well as healthy older respondents could be observed, were as follows: sunbathing in adulthood, number of holidays at the seaside, and number of solarium visits (although a slightly rising trend can be observed in this pattern).

The most alarming results include: duration of sun exposure - observed behavior of the young generation is even worse than that observed for oncological patients - up to $70.43 \%$ of young people $(66.67 \%$ in oncological patients $(\mathrm{p}=0.2824)$; $31.79 \%$ in healthy older respondents $(\mathrm{p}<0.0001))$ stayed out all day long while sunbathing, which included the period of maximum risk (11 AM to $3 \mathrm{PM}$ ); the use of sunscreens in adulthood - the ratio of those who used sunscreen occasionally vs. regularly reached its worst value for the young generation (66.09\% vs. $28.26 \%$ ); this ratio is almost opposite for older healthy respondents $(27.15 \%$ vs. $62.91 \%$; $\mathrm{p}<0.0001)$, and in patients with $\mathrm{CM}$ the ratio is $(56.48 \%$ vs. $27.78 \%$; $\mathrm{p}=0.0131$ ); number of holidays in the mountains also represent an alarming factor $-50.87 \%$ of young respondents had regular mountain holidays each winter, spring and summer vs. $20.53 \%$ of older healthy respondents $(\mathrm{p}<0.0001)$ and $31.48 \%$ of patients with $\mathrm{CM}(\mathrm{p}<0.0001)$. 
Logistic Regression. Based on the answers of our respondents, three logistic regression models were constructed:

1. MELANOMA vs. OLD - patients with CM vs. older healthy respondents

2. YOUNG vs. OLD - older healthy respondents vs. healthy adolescents

3. MELANOMA vs. YOUNG - patients with CM vs. healthy adolescents

The basic logistic regression characteristics of all three models, which are summarized in Table 2, show that all three models are statistically significant and interpolate data adequately. The classification ability of all three models is very good - 76.2\% (MELANOMA vs. OLD), 83.0\% (YOUNG vs. OLD) and 91.2\% (MELANOMA vs. YOUNG) and the discrimination power measured using ROC analysis was good [21] for the model MELANOMA vs. OLD (area under the ROC curve AUC 0.856) and very good for the models YOUNG vs. OLD (AUC 0.920) and MELANOMA vs. YOUNG (AUC 0.953). Statistically significant regression coefficients for all three models are presented in Tables 3, 4 and 5.

\section{Interpretation of Regression Coefficients.}

MELANOMA vs. OLD (Table 3). The chance of the CM formation increased in the following cases: Sunburns during childhood: more than 10 times vs. never (OR 4.34; CI 1.2015.63 ) and occasionally vs. never (OR 4.36; CI 1.60-11.92). Use of sunscreen during childhood: never vs. occasionally (OR
Table 2. Overview of logistic regression models and results of statistical evaluation criteria

\begin{tabular}{lccc}
\hline Model: & $\begin{array}{c}\text { MELANOMA } \\
\text { vs. } \\
\text { OLD }\end{array}$ & $\begin{array}{c}\text { YOUNG } \\
\text { vs. } \\
\text { OLD }\end{array}$ & $\begin{array}{c}\text { MELANOMA } \\
\text { vs. } \\
\text { YOUNG }\end{array}$ \\
\hline $\begin{array}{l}\text { Omnibus test - 2LL } \\
\text { Hosmer-Lemeshow test }\end{array}$ & 0.000 & 0.000 & 0.000 \\
for goodness of fit** & 0.601 & 0.840 & 0.475 \\
$\begin{array}{l}\text { Nagelkerke } \mathrm{R}^{2 * * *} \\
\text { \% of correctly classified }\end{array}$ & 0.471 & 0.640 & 0.767 \\
AUC $^{\dagger}$ & 76.2 & 83.0 & 91.2 \\
Sensitivity $^{\dagger \dagger}$ & 0.856 & 0.920 & 0.953 \\
Specificity $^{\dagger+}$ & 70.48 & 73.77 & 78.10 \\
\hline
\end{tabular}

* Omnibus test $-2 L L$ of model coefficients gives an indication of whether the model with the independent variables fits the data better than the baseline model ("intercept only" model). If the test was significant the "final model" fits better than the baseline model

** Hosmer-Lemeshow test compares the actual result for each respondent with the outcome predicted with the model. If this test was non-significant the observed and expected counts should be similar and the model fits the data

${ }^{* * *}$ Nagelkerke $R^{2}$ indicates the improvement in fit of the model with predictors over the baseline model ( 0 - 0.1 - poor improvement, 0.1 - 0.3 modest improvement $0.3-0.5$ moderate and more than 0.5 strong improvement)

$\dagger$ AUC (Area under the ROC curve) is a measure of the accuracy of the model, which depends on how well the model separates the groups being tested $\dagger \dagger$ Sensitivity is the power to identify positives

$\dagger \dagger \uparrow$ Specificity is the power to identify negatives

Table 3. Odds ratios (OR), 95\% Confidence Intervals (CI) and significance levels of Wald's statistic (p) of differences in answers of the questionnaire between patients with $\mathrm{CM}(\mathrm{N}=216)$ and older healthy respondents $(\mathrm{N}=302)$.

\begin{tabular}{|c|c|c|c|c|}
\hline Variable & OR & $95 \%$ CI & $\mathrm{p}$ & Risk for adolescents \\
\hline \multicolumn{5}{|l|}{$\begin{array}{l}\text { Sun burns in childhood } \\
\text { NEVER vs. }\end{array}$} \\
\hline OCCASIONALLY (less than 10) & 4.363 & $1.597-11.917$ & $0.004^{*}$ & \\
\hline FREQEUENT (more than 10) & 4.336 & $1.203-15.632$ & 0.025 & \\
\hline \multicolumn{5}{|l|}{$\begin{array}{l}\text { Use of sunscreen in the childhood } \\
\text { OCCASIONALLY vs. }\end{array}$} \\
\hline REGULARLY & 0.211 & $0.058-0.740$ & 0.018 & \\
\hline NEVER & 2.916 & $1.351-6.296$ & 0.006 & \\
\hline \multicolumn{5}{|l|}{$\begin{array}{l}\text { Exposure to sun radiation } \\
\text { AT OUTDOOR HOBBY vs. }\end{array}$} \\
\hline ACTIVE SUNBATHING & 0.307 & $0.107-0.878$ & 0.028 & \\
\hline \multicolumn{5}{|l|}{ Time duration of sun exposure } \\
\hline ALL DAY LONG & 5.153 & $2.499-10.622$ & 0.000 & \\
\hline \multicolumn{5}{|l|}{$\begin{array}{l}\text { Use of the sunscreen in the adulthood } \\
\text { OCCASIONALLY vs. }\end{array}$} \\
\hline REGULARLY & 0.192 & $0.085-0.433$ & 0.000 & \\
\hline \multicolumn{5}{|l|}{$\begin{array}{l}\text { Holydays in the mountains } \\
\text { NEVER vs. }\end{array}$} \\
\hline OCCASIONALLY & 3.704 & $1.262-10.867$ & 0.017 & \\
\hline EVERY WINTER, SPRING, SUMMER & 6.653 & $1.916-23.095$ & 0.003 & \\
\hline
\end{tabular}

${ }^{*}$ Only statistically significant results are presented 
Table 4. Odds ratios (OR), 95\% Confidence Intervals (CI) and significance levels of Wald's statistic (p) of differences in answers of the questionnaire between older healthy respondents $(\mathrm{N}=302)$ and adolescents $(\mathrm{N}=460)$.

\begin{tabular}{|c|c|c|c|c|}
\hline Variable & OR & $95 \% \mathrm{CI}$ & $\mathrm{p}$ & Risk for adolescents \\
\hline \multicolumn{5}{|l|}{ Sun burns in childhood } \\
\hline \multicolumn{5}{|l|}{ NEVER vs. } \\
\hline OCCASIONALLY (less than 10) & 0.336 & $0.166-0.700$ & $0.004^{*}$ & \\
\hline FREQEUENT (more than 10) & 0.046 & $0.008-0.280$ & 0.001 & \\
\hline \multicolumn{5}{|l|}{ Use of sunscreen in the childhood } \\
\hline \multicolumn{5}{|l|}{ OCCASIONALLY vs. } \\
\hline REGULARLY & 4.525 & $1.919-10.638$ & 0.001 & \\
\hline NEVER & 0.124 & $0.045-0.345$ & 0.000 & \\
\hline \multicolumn{5}{|l|}{ Time duration of sun exposure } \\
\hline \multicolumn{5}{|l|}{ UNTIL $11 \mathrm{AM}$ and FROM 03 PM vs. } \\
\hline ALL DAY LONG & 7.874 & $3.774-16.393$ & 0.000 & $!$ \\
\hline \multicolumn{5}{|l|}{ Use of the sunscreen in the adulthood } \\
\hline \multicolumn{5}{|l|}{ OCCASIONALLY vs. } \\
\hline REGULARLY & 5.155 & $2.475-10.752$ & 0.000 & \\
\hline NEVER & 5.291 & $1.129-25.000$ & 0.035 & $!$ \\
\hline \multicolumn{5}{|l|}{ Holydays in the mountains } \\
\hline \multicolumn{5}{|l|}{ NEVER vs. } \\
\hline EVERY WINTER, SPRING, SUMMER & 4.651 & $1.236-17.544$ & 0.023 & ! \\
\hline
\end{tabular}

${ }^{*}$ Only statistically significant results are presented

$=2.92 ; \mathrm{CI}=1.35-6.30)$, occasionally vs. regularly $(\mathrm{OR} 4.74$ = 1/0.211; CI 0.058-0.740). Sun Exposure: during outdoor hobbies vs. during active sunbathing (OR $3.26=1 / 0.307$; CI 0.11-0.88). Duration of sun exposure: all day long vs. until 11 AM and after 3 PM (OR 5.15; CI 2.50-10.62). Use of sunscreen in adulthood: occasionally vs. regularly (OR $5.26=1 / 0.19$; CI 0.085-0.43) and finally, the number of Holidays in the mountains: every winter, spring and summer vs. never (OR 6.65; CI 1.92-23.10), and occasionally vs. never (OR 3.70; CI 1.26-10.87).

YOUNG vs. OLD (Table 4). The more responsible sun exposure behavior in the young generation compared with older respondents was observed in the following parameters: Sunburns during childhood: more than 10 times vs. never (OR $21.82=1 / 0.046$; CI $0.01-0.28$ ) and occasionally vs. never (OR $2.98=1 / 0.336$; CI 0.17-0.70). Use of sunscreen during childhood: never vs. occasionally (OR $8.04=1 / 0.124$; $\mathrm{CI}=0.05-0.35)$, occasionally vs. regularly (OR 4.53; CI 1.92-10.64). Use of sunscreen in adulthood: occasionally vs. regularly (OR 5.15; CI 2.48-10.75). In contrast, the more risky sun exposure behavior among adolescents was illustrated by the following answers: Duration of sun exposure: all day long vs. until 11 AM and after 3 PM (OR 7.87; CI 3.77-16.39). Use of sunscreen in adulthood: never vs. occasionally (OR 5.29; CI 1.13-25.00) and number of Holidays in the mountains: regularly every winter, spring and summer vs. never (OR 4.65; CI 1.24-17.54).

MELANOMA vs. YOUNG (Table 5). Much better sun exposure behavior among young people versus oncological patients was observed in early childhood: Sunburns during childhood: more than 10 times vs. never (OR 343.86; CI 38.24-3091.74) and occasionally vs. never (OR 39.37; CI 9.22-168.06) and in the Use of sunscreen during childhood: never vs. occasionally $(\mathrm{OR}=54.62 ; 95 \% \mathrm{CI}=13.97-213.63)$ and occasionally vs. regularly $(\mathrm{OR} 4.17=1 / 0.240 ; 95 \% \mathrm{CI}=0.078-0.74)$. The last statistically significant difference was associated with the answer to the question regarding Sun exposure: during outdoor hobbies vs. during active sunbathing (OR $6.99=1 / 0.143$; CI $=0.03-0.71)$. Since all young respondents are still students, evaluating the degree of riskiness of this behavior pattern is very difficult.

\section{Discussion}

The first model of our study, in which sun exposure behavior was compared between elderly healthy people and oncological patients, confirmed many risk factors which had been previously described in numerous publications. These risk factors included frequent episodes of sunburn and underuse of sunscreen during childhood [22-25]. Extensive sun exposure during childhood plays an important role in rapid nevi development, particularly in areas of intensive sun exposure [26,27]. Given that the risk factors for melanoma and higher nevus counts are the same (fair-skinned phototype, greater UV exposure, higher frequency and severity of sunburns), the association between the presence of numerous nevi and sun protection habits during childhood had been expected, and was confirmed in our cohort of patients. A strong positive association between higher nevus counts and sunburn episodes (results of the Pearson's $\chi^{2}$ test: never vs. occasionally $\mathrm{p}<0.0001$, never vs. frequent $\mathrm{p}<0.0001$ and occasionally vs. frequent $\mathrm{p}=0.0152$ ) and a negative as- 
Table 5. Odds ratios (OR), 95\% Confidence Intervals (CI) and significance levels of Wald's statistic (p) of differences in answers of the questionnaire between patients with $\mathrm{CM}(\mathrm{N}=216)$ and adolescents $(\mathrm{N}=460)$.

\begin{tabular}{|c|c|c|c|c|}
\hline Variable & OR & $95 \% \mathrm{CI}$ & $\mathrm{p}$ & Risk for adolescents \\
\hline \multicolumn{5}{|l|}{$\begin{array}{l}\text { Sun burns in childhood } \\
\text { NEVER vs. }\end{array}$} \\
\hline OCCASIONALLY (less than 10) & 39.373 & $9.224-168.061$ & $0.000^{*}$ & \\
\hline FREQEUENT (more than 10) & 343.863 & $38.244-3091.735$ & 0.000 & \\
\hline \multicolumn{5}{|l|}{$\begin{array}{l}\text { Use of sunscreen in the childhood } \\
\text { OCCASIONALLY vs. }\end{array}$} \\
\hline REGULARLY & 0.240 & $0.078-0.784$ & 0.013 & \\
\hline NEVER & 54.622 & $13.966-213.625$ & 0.000 & \\
\hline \multicolumn{5}{|l|}{$\begin{array}{l}\text { Exposure to sun radiation } \\
\text { AT OUTDOOR HOBBY vs. }\end{array}$} \\
\hline ACTIVE SUNBATHING & 0.143 & $0.029-0.708$ & 0.017 & ? \\
\hline
\end{tabular}

${ }^{*}$ Only statistically significant results are presented

sociation between higher nevus counts and the regularity of sunscreen use during childhood (never vs. occasionally $\mathrm{p}=$ 0.0002 and never vs. regularly $\mathrm{p}=0.0118$ ) were found. Within the cohort of our respondents, those who worked indoors and took part in outdoor hobbies were more likely to develop $\mathrm{CM}$ than those who were exposed to sun radiation during active sunbathing. This is likely due to one of the typical Czech lifestyles, i.e. gardening or "going to the cottage," in combination with inadequate sun protection, during which unplanned sun-tanning occurs, with the longest and most frequent exposure during the strong midday sun (11 AM - 3 PM). Similar results have been found by other authors $[28,29]$. Additional important risk factors include sunbathing during times associated with the greatest UV risk (11 AM - 3 PM), complete or inadequate sunscreen use during adulthood, as well as regular holidays in the mountains during the winter, spring and summer. These results agree with the observations of Koster et al. and Moehrle [30,31].

By using the next two models, in which the sun exposure and sun protection habits of adolescents were compared to those of healthy, older respondents and oncological patients, both responsible and alarming sun exposure behavior patterns in the younger generation were discovered. The most responsible sun protection habits indicated a very low percentage occurrence of frequent sunburn episodes and a very low percentage of never having used sunscreen during childhood (ages 0 - 12). However, these two factors were particularly affected by the behaviour and responsibility of parents or caretakers. By contrast, when parents lose their influence over children during adolescence and beyond (age $>18$ ), the level of responsible behavior in young people significantly declines relative to personal health and, in some aspects, is even worse than the sun-related behavior observed in oncological patients. These irresponsible behaviors include: remaining in the sun all day, including those times posing the greatest UV risk (11 AM to $3 \mathrm{PM}$ ) and incomplete or inadequate use of sunscreen when sunbathing during adulthood - most young people use sunscreen only occasionally, instead of applying it regularly. Also alarming was the fact that young people spend time in the mountains much more often than that seen in oncological patients, and are thereby considerably increase the risk of CM formation at older ages (extreme UV exposure in outdoor sports such as skiing and mountaineering is amplified by reflection from snow and ice-covered surfaces [31]). A plausible explanation for these alarming results is the social and economic changes associated with the lifestyle changes involved in the adoption of increased risk behaviour patterns [32,33], which is occurring earliest in younger individuals [34]. All of these facts have been confirmed by numerous studies which suggest that the younger generation is the most endangered population group, while at the same time, being the most resistant to preventive campaigns [18-20].

Many studies concerning the prevention of skin cancers, including malignant cutaneous melanoma and sun protection, have confirmed our results. They reported that, while children have positive sun protective behavior [35,36], which is largely influenced by their parents and school policies (in the most endangered locations, e.g. Australia, the USA and the United Kingdom), adolescents have the lowest skin protection rates among all age groups, despite a high level of knowledge regarding the potential danger and harm of sun overexposure [37]. In a study by Lupton and Gaffney, adolescents stated that they deliberately used sunscreen with a low protection factor (SPF) and also delayed sunscreen application in order to get a tan [38]. Additionally, at the time when parent influence is declining, peer group influence is increasing. Adolescent sun protective behaviors are significantly affected by the opinions and perceived social norms within their peer group [39]. Within adolescent groups, a tan is still perceived positively, and having one is still considered to be a sign of beauty and good health.

The above observations, as well as those from our own results, indicate a necessity to develop innovative strategies that will reinforce positive sun protective behavior in adolescents and successfully transfer this behavior into adulthood, at which 
time these young adolescents will become the caretakers and role models for their own children.

The level of attention being directed toward young people should be increased. This study will hopefully intensify pressure on the Czech health authorities to develop more effective, more assertive and more persuasive preventive campaigns for our adolescents. One important step in the prevention of malignant melanomas may be the introduction of preventive programs into primary and secondary schools in the Czech Republic, where education regarding responsible sun exposure and sun protective behavior is currently lacking or inadequate.

\section{References}

[1] OSTERLIND A. Epidemiology on malignant melanoma in Europe. Acta Oncol. 31: 903-908, 1992. http://dx.doi. org/10.3109/02841869209089727

[2] DE VRIES E, COEBERGH JW. Cutaneous malignant melanoma in Europe. Eur J Cancer 40: 2355-66, 2004. http://dx.doi. org/10.1016/j.ejca.2004.06.003

[3] Cancer Incidence 2008 in the Czech Republic. IHIS of the Czech Republic. http://www.uzis.cz/publikace/novotvary2008 [accessed on 12 July 2011]

[4] LEE PY, SILVERMAN MK, RIGEL DS, VOSSAERT KA, KOPF AW, et al. Level of education and the risk of malignant melanoma. J Am Acad Dermatol. 26: 59-63, 1992. http:// dx.doi.org/10.1016/0190-9622(92)70007-3

[5] KIRKPATRICK CS, LEE JAH, WHITE E. Melanoma risk by age and socio-economic status. Int J Cancer. 40: 1-4, 1990. http://dx.doi.org/10.1002/ijc.2910460102

[6] TURNER, M. Sun safety: avoiding noonday sun, wearing protective clothing, and the use of sunscreen. J Natl Cancer Inst. 90: 1854-1855, 1998. http://dx.doi.org/10.1093/jnci/ $\underline{90.24 .1854}$

[7] MACBETH AE, GRINDLAY DJ, WILLIAMS HC. What's new in skin cancer? An analysis of guidelines and systematic reviews published in 2008-2009. Clin Axp Dermatol; 36(5): 353-8, 2011.

[8] HART KM, DEMARCO RF. Primary prevention of skin cancer in children and adolescents: a review of the literature. J Pediatr Oncol Nurs. 25: 67-78, 2008. http://dx.doi.org/ $\underline{10.1177 / 1043454208314499}$

[9] KHALAT M, VAIL A, PARKIN M, GREEN A. Mortality from melanoma in migrants to Australia: variation by age at arrival and duration of stay. Am J Epidemiol. 135: 1103-13, 1992.

[10] HOLMAN CA, ARMSTRONG BK, HEENAN PJ, BLACKWELL JB, CUMMING FJ, et al. The causes of malignant melanoma: results from the West Australian Lions Melanoma Research Project. Recent results. Cancer Res. 102: 18-37, 1986. http://dx.doi.org/10.1007/978-3-642-82641-2 3

[11] ELWOOD JM, GALLAGHER RP, HILL GB, PEARSON JC. Cutaneous melanoma in relation to intermittent and constant sun exposure in the Western Canada Melanoma Study. Int J Cancer. 35: 427-33, 1985. http://dx.doi.org/10.1002/ ijc. 2910350403
[12] GALLAGHER RP, SPINELLI JJ, LEE TK. Tanning beds, sunlamps and risk of cutaneous malignant melanoma. Cancer Epidemiol Biomarkers Prev. 14: 562-6, 2005. http://dx.doi. org/10.1158/1055-9965.EPI-04-0564

[13] DEN OUTER, PN, SLAPER H, KAUROLA J, LINDFORS A, KAZANTZIDIS A, et al. Reconstructing erythe $\neg$ mal ultraviolet radiation levels in Europe for the past 4 decades, J. Geophys. Res., 115, D10102, doi: 10.1029/2009JD012827, 2010. http://dx.doi.org/10.1029/2009JD012827

[14] LANGE JR PALIS BE, CHANG DC, SOONG SJ, BALCH CM. Melanoma in children and teenagers: An analysis of patients from the National Cancer Data Base. J Clin Oncol 2007 Apr 10; 25:1363-8. http://dx.doi.org/10.1200/JCO.2006.08.8310

[15] LIU T, SOONG SJ. Epidemiology of malignant melanoma. Surg Clin North Am. 1996 Dec;76:1205-22. http://dx.doi. org/10.1016/S0039-6109(05)70511-9

[16] DE GUIRE L, THERIAULT G, ITURRA H, PROVENCHER $S$, CYR D,et al. Increased incidence of malignant melanoma of the skin in workers in a telecommunications industry. Br J Ind Med. 1988 December; 45: 824-828

[17] ARMSTONG BK, KRICKER A. How much melanoma is caused by sun? Melanoma Res. 3: 395-401, 1993. http://dx.doi. org/10.1097/00008390-199311000-00002

[18] GLANTZ SA, MANDEL LL. Since school-based tobacco prevention programs do not work, what should we do? J Adolesc Health. 36: 157-9, 2005. http://dx.doi.org/10.1016/ j.jadohealth.2005.01.001

[19] SKARA S, SUSSMAN S. A review of 25 long-term adolescent tobacco and other drug use prevention program evaluations. Prev Med. 37: 451-74, 2003. http://dx.doi.org/10.1016/S00917435(03)00166-X

[20] TOBLER N, ROONA M, OCHSHORTN P, MARSHALL DG, STREKE AV, et al. School-based adolescent drug prevention programs: 1998 meta-analysis. J Prim Prev. 20: 275-336, 2000. http://dx.doi.org/10.1023/A:1021314704811

[21] TAPE TG. The Area Under an ROC Curve [online], University of Nebraska Medical Center. In: Interpreting Diagnostic Tests, University of Nebraska Medical Center. http://gim.unmc. edu/dxtests/ROC3.htm [accessed on 12 July 2011]

[22] ENGLISH DR, MILNE E, SIMPSON JA. Ultraviolet radiation at places of residence and the development of melanocytic nevi in children (Australia). Cancer Causes Control. 17: 103-107, 2006. http://dx.doi.org/10.1007/s10552-005-0425-0

[23] FRITSCHI L, MCHENRY P, GREEN A, MACKIE R, GREEN $\mathrm{L}$, et al. Naevi in schoolchildren in Scotland and Australia. Br J Dermatol. 1: 599-603, 1994 http://dx.doi.org/10.1111/j.13652133.1994.tb13106.x

[24] JIRASKOVA M, JIRASEK L. Is sunbathe in childhood appropriate or damaging? Pediatrie pro praxi. 3: 163-167, 2007 (In Czech).

[25] LEA CS, SCOTTO JA, BUFFLER PA, FINE J, BARNHILL RL, et al. Ambient UVB and Melanoma Risk in the United States: A Case-Control Analysis. Ann Epidemiol. 17: 447-453, 2007. http://dx.doi.org/10.1016/j.annepidem.2007.01.030

[26] AALBORG J, MORELLI JG, MOKROHISKY ST, ASIGIAN NL, BEYRS TE, et al. Tanning and increased nevus development in very-light-skinned children without red hair. Arch 
Dermatol. 145: 989-96, 2009. http://dx.doi.org/10.1001/ archdermatol.2009.193

[27] NEWTON-BISHOP JA, CHANG YU, ILES MM, TAYLOR JC, BAKKER B, et al. Melanotic nevi, nevus genes and melanoma risk in a large case-control study in the United Kingdom. Cancer Epidemiol Biomarkers Prev. 19: 2043-54, 2010. http:// dx.doi.org/10.1158/1055-9965.EPI-10-0233

[28] PARENT ME, ROUSSEAU MC, EL-ZEIN M, LATREILLE B, DESY $M$, et al. Occupational and recreational physical activity during adult life and the risk of cancer among men. Cancer Epidemiology 35: 151-159, 2011. http://dx.doi.org/10.1016/ j.canep.2010.09.004

[29] ARMSTRONG BK, KRICKER A. The epidemiology of UV induced skin cancer. Journal of Photochemistry and Photobiology B: Biology 63:8-18, 2001. http://dx.doi.org/ 10.1016/S1011-1344(01)00198-1

[30] KOSTER B, THORGAARD C, PHILLIP A, CLEMMENSEN IH. Vacations to sunny destinations, sunburn, and intention to tan: A cross-sectional study in Denmark, 2007-2009. Sncan J Public Health. 39: 64-69, 2011. http://dx.doi.org/10.1177/ $\underline{1403494810391526}$

[31] MOEHRLE M. Outdoor sports and skin cancer. Clin Deramtol. 26: 12-15, 2008. http://dx.doi.org/10.1016/j.clind ermatol.2007.10.001

[32] DOLL R. Progress against cancer: an ethiological assessment. Am J Epidemiol, 134: 675-88, 1991.
[33] GLASS AG, HOOVER RN. The emerging epidemic of melanoma and squamous cell skin cancer. J Am med Ass. 262: 2097-2100, 1989. http://dx.doi.org/10.1001/ jama.1989.03430150065027

[34] AASE A, ALMAS R. The diffusion of cardiovascular disease in Norwegian farming community: a combination of morbidity and mortality data. Soc Sci Med. 29: 1027-33, 1989. http://dx.doi.org/10.1016/0277-9536(89)90060-9

[35] HOERSLY L, CHRALTON A, WATERMAN C. Current action for skin cancer risk reduction in English schools: pupils' behaviour in relation to sunburn. Health Education Research, 17, 715-31, 2002

[36] DEVOS SA, BAEYNES K, VAN HOECKE L. Sunscreen use and skin protection behavior on the Belgian beach. International journal of Dermatology, 42, 352-6, 2003. http://dx.doi. org/10.1046/j.1365-4362.2003.01665.x

[37] ROBINSON JK, RADEMAKER AW. Sun protection by families at the beach. Journal of American Academy of Dermatology, 152, 466-70, 1998

[38] LUPTON D, GAFFNEY D. Discourses and practices related to sun tanning and solar protection among young Australians. Health Education Research, 11, 147-59, 1996. http://dx.doi. org/10.1093/her/11.2.147

[39] WILCHSTROM L. Predictors of Norwegian adolescents' sunbathing and use of sunscreen. Health Psychology, 13, 412-20, 1994 